\title{
Wide Range Variable Voltage Transformerless DC Power Supply Using TRIAC
}

\author{
Augustinus Sujono ${ }^{1}$, Feri Adriyanto ${ }^{2}$, Hari Maghfiroh ${ }^{3}$, Joko Slamet Saputro ${ }^{4}$, Agus Ramelan ${ }^{5}$ \\ Dept. of Electrical Engineering \\ Universitas Sebelas Maret \\ Surakarta, Indonesia \\ 1 agus.sjn.te16@gmail.com, ${ }^{2}$ feri.adriyanto@ staff.uns.ac.id, ${ }^{3}$ hari.maghfiroh@gmail.com, ${ }^{4}$ jssaputro89@ staff.uns.ac.id, \\ 5 agusramelan@staff.uns.ac.id
}

\begin{abstract}
Variable voltage DC power supply that has wide range of power, lightweight and inexpensive is quite difficult to obtain. This research designs and tests a DC power supply without a transformer using switching technology that utilizes TRIAC. The 220 Volt AC power source is converted to DC electricity by the method of cutting off some $\mathrm{AC}$ waves signal, using TRIAC, and then rectifying it with diodes and filters. DIAC functions as a trigger TRIAC at the specified time, by turning the variable resistor. The test results show that the output DC power voltage can be adjusted from 5 Volts to 75 Volts by adjusting the DIAC resistance and the load resistance. The results of the series image characteristics are given 2 dimensional and 3-dimensional graphics.
\end{abstract}

Keywords-power supply, converter, TRIAC, Tranformerless, Switching

\section{INTRODUCTION}

Variable voltage DC power supply is needed in many activities, but what is available is mostly large, heavy, expensive and limited range. Those that have a wide range, are lightweight and cheap are hard to come by, so new designs are needed that answer the problem. DC electricity needed is low voltage, which is generated from 220 Volt AC electricity using a converter, which is a transformer as a voltage reducer. Rectifier diodes and filters are added as voltage rectifiers and smoothers. The problem occurs because the transformer is large, heavy, expensive and has limited power capability. Then it is necessary to design an AC to DC converter that utilizes new technology, without the use of a transformer and referred to as a trans fomerless DC power supply.

The switching technology on TRIAC (triode for altemating current) and DIAC (diode for alternating current) can be used as a converter, for the need for AC to DC power conversion. Moreover, TRIAC is available which provides large power, making converters without transformers workable. Provides an adjus table output voltage by installing a potentio resistor circuit in the DIAC circuit to cut off a portion of the AC power source waveform, at the specified time.

TRIAC and DIAC belong to the thyristor group which is a 4-layer semiconductor that uses internal feedback that can provide latching behavior, so that it can function as a switch [1]. In the thyristor group there are also SCR (silicon controlled rectifier), GCS (gate controlled switch), SCS (Silicon controlled switch). TRIAC is two SCR which is equivalent, so that it can be passed in two-way current, also known as silicon bidirectional thyristor [2]. DIAC can be passed two-way current at a voltage above the ignition voltage, so it can be used as a trigger for TRIAC. TRIAC and DIAC can work at high voltages so they can be used to control AC electric currents, which can cut some AC power waves at certain positions. Thus the TRIAC and DIAC circuits can limit the passing electric power, so that high electrical voltage can be low or is called capable of acting as a converter. In order to convert $\mathrm{AC}$ waves to $\mathrm{DC}$ rectifier diodes and capacitors can be used as a voltage output refiner. Here some DC power supply technology:

\section{- DC power supply using transformer}

The trans former is two coil conductors in the iron core, consisting of primary and secondary winding so that it can be used as a transfer of AC electrical power through electromagnetic induction. The AC mains voltage is converted by the trans former as needed and to be made into DC electricity by diodes and installed capacitors to smooth the DC power output.

Figure 1 is a basic DC power supply circuit that uses a transformer. This circuit has been available for a long time and is a reliable power supply circuit, but the voltage generated is fixed, not variable. If needed the voltage change can be done by changing the edges (tep) of the different winding joints.

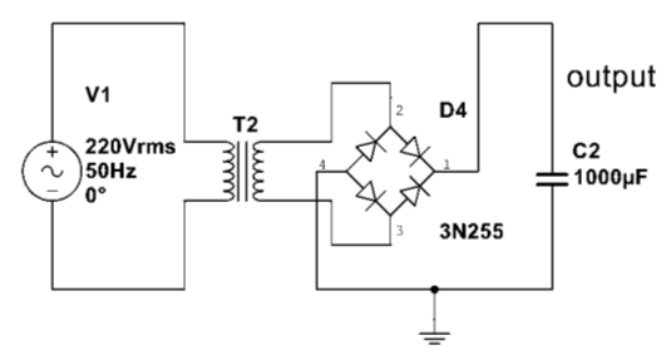

Fig. 1. Converter using transformer and rectifier

- DC power supply with a initial(pre) resistor

Initial resistors in the AC power circuit in the form of resistors and capacitors can function as voltage reducers, because they provide current resistance. The impedance of the resistor with the capacitor is able to provide resistance to the current, but it caus es heat and caus es power loss. Besides that the voltage drop is limited and the voltage can not be fixed, because it depends on the current passing. Then the effect of this initial resistance is power losses and the working range of this power supply, which gives limited power.

The impedance [3] 


$$
\mathrm{Z}=R_{1}+\frac{R_{2}}{\omega R_{2} C+1}
$$

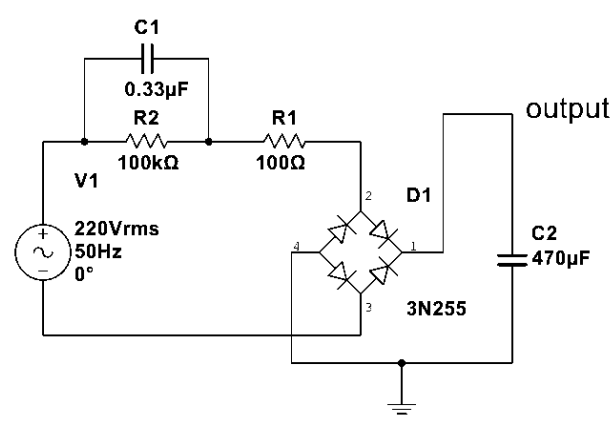

Fig. 2. Converter using pre-resistor and rectifier

Figure 2 shows the DC power supply circuit us ing initial resistance as a voltage reduction and rectifier with the capacitor as a rectifier and filter, but the power efficiency is low, due to power losses at the initial resistor.

- DC power supply using s witching technology

Cutting some AC power waves will be able to reduce the transfer of power so that the average power will be smaller, so it will also reduce the output voltage.

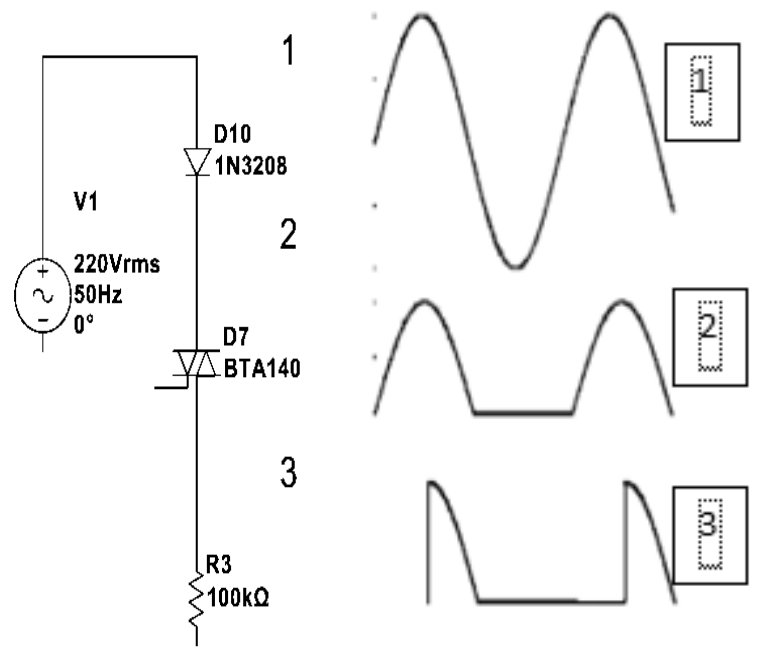

Fig. 3. Electric power of cutted wave

$$
\begin{aligned}
& \mathrm{V}_{\mathrm{dc}}=0.318 \mathrm{~V}_{\mathrm{m}} \\
& \mathrm{V}_{\mathrm{dc}}=0.154 \quad \mathrm{~V}_{\mathrm{m}} \\
& \mathrm{V}_{\mathrm{dc}}=0.78 \mathrm{~V}_{\mathrm{m}}
\end{aligned}
$$$$
\text { Current : } i=I_{m} \sin (\omega t) ; I_{\text {eff }}=\frac{I_{m}}{\sqrt{2}}
$$$$
\text { Voltage }: v=V_{m} \sin (\omega t) ; V_{\text {eff }}=\frac{V_{m}}{\sqrt{2}}
$$$$
\text { Full wave power: } P=V_{\text {eff }} I_{\text {eff }}
$$

Figure 3 shows AC voltage wave and current. On picture describes with cut a part of AC electric wave can turn down the power and voltage [1]. On left figure shows AC full wave, halft wave and quarter wave.

\section{A. TRIAC Characteristics}

TRIAChas the ability as a switch, which can be closed or opened with extemal control, namely through the gate. When the gate is voltage (ON), it is like a closed switch, so it can pass the current. It will be the gate voltage is disconnected (OFF) then like a switch is opened, so the current is cut off. This can be done at high frequency and high voltage. The ability to handle large currents is also available. Features of TRIAC shows below:

- Blocking Voltage to $800 \mathrm{~V}$

- On-Statc Current Rating of 16 A RMS at $25^{\circ} \mathrm{C}$

- Uniform Gate Trigger Currents in Threc Quadrants

- High Immunity to $\mathrm{dV} / \mathrm{dt}-1000 \mathrm{~V} / \mathrm{us}$ minimum at $125^{\circ} \mathrm{C}$

- Minimizes Snubber Networks for Protection

- Industry Standard TO-220AB Package

- High Commutating $\mathrm{dl} / \mathrm{dt}-8.5 \mathrm{~A} / \mathrm{ms}$ minimum at $125^{\circ} \mathrm{C}$

- Internally Isolated (2500 V RMS)

- These Devices are Pb-Free and are RoHS Compliant*

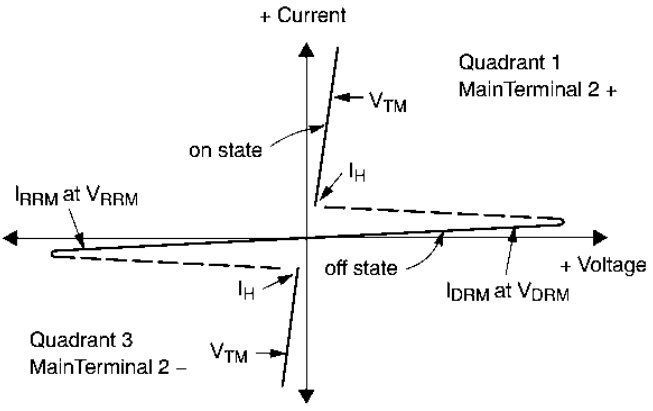

Fig. 4. TRIAC characteristics [2]

Figure 4 shows the characteristics of TRIAC BTA16, which is able to handle 800 Volt voltage and on-state current rating at 16 Amperes, at high frequencies, so it does not require complicated protection.

\section{B. DIAC Characteristics}

DIAC is a gate that can open by itself when given a voltage above the triggering voltage and can flow in both directions. DIAC can be used for TRIAC triggers to be able to flow current at a certain time. In AC electricity the waves will rise and fall, so that it can be used to trigger DIAC according to the frequency of the voltage.

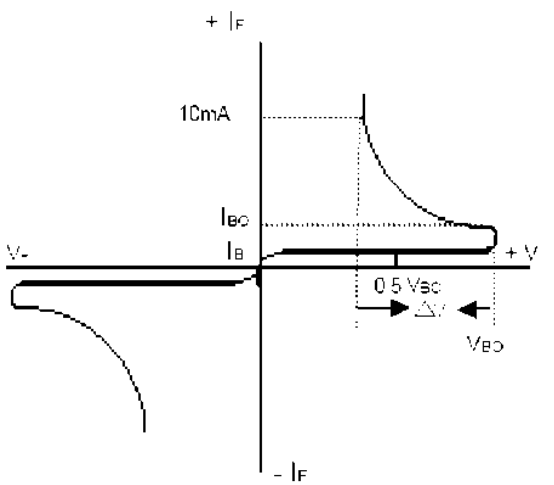

Fig. 5. DIAC Characteristics [4] 
Figure 5 shows the characteristics of DIAC DB3 which has a triggering voltage at a stable voltage at high temperatures. Its physical form is very small and lightweight.

\section{SMPS Technology}

Switch chopping allows cutting of electrical waves can be cut into small pieces at high frequencies, so that electric power can be converted as needed. Besides TRIAC, there are also available MOSFETs (metaloxide field effect transistors) and IGBT (insulated gate bipolar transistors) which have the ability to switch at high frequencies and large currents. SMPS technology (switch mode power supply) provides the possibility to develop a flexible, efficient, large, lightweight and economical power supply.

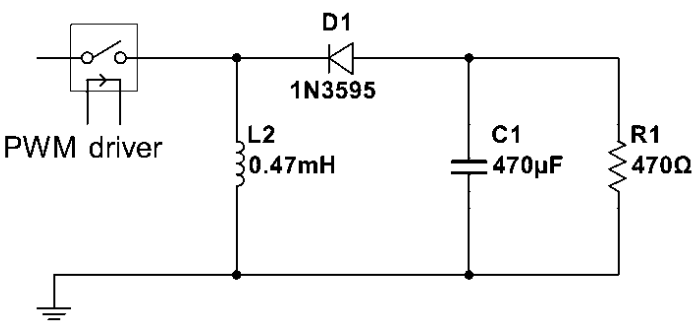

Fig. 6. Buck - Boost Converter [5]

Figure 6 shows a buck-boost converter circuit that can convert AC power and produce DC power output with variable voltage, which is controlled by a PWM driver. In this case the PWM driver will trigger the MOSFET s witch to flow the current at a certain frequency, with a certain DC (duty cycle). PWM drivers can be either a microcontroller or a flexible flip-flop that is able to work at high voltages [6].

The switching technology using TRIAC has been success fully designed for use in nonres is tive lighting sources by Chih Wei Lin at.all [7], an AC-DC converter design to provide good power quality as well as wide linear nonflowing dimming control range. A variable PFC (powerfactor-correction) output voltage modulation method is proposed to enhance the dimming control range.

TRIAC can also be used for power control phases, and synchronization is done by: Peter I. Yakimov [8], An approach for digital control of the ignition pulses generation using the possibilities of the enhanced capture timer module of the microcontrollers from the MC9S12D-Family and an algorithmfor main synchronization is proposed.

The input filter on the AC / DC converter for dimmable LED lamps has been designed by: Montu Doshi at.all [9], explained: This paper presents EMI (electromagnetic interference) filter input and damping circuits for phase dimmable LED lamps. An input EMI filter is implemented as part of LED lamp power supplies to comply with conducted emission standards set by regulatory agencies. The use of conventional EMI filter configurations are limited in this application due to the absence of earth (chassis) connection and the presence of stringent mechanical size constraints. This paper describes alternative EMI filter topologies suitable for 2-wire input connections present in Edison or Bayonet sockets. Criteria for achieving dimmer compatibility are introduced and the impact of an EMI filter on phase dimming operation is studied. The influence of different damping networks on transient performance of systems is analyzed using pole-zero mapping techniques and minimum damping requirements are established. A step-bystep procedure for EMI filter and damping network design is outlined and verified for a $16 \mathrm{~W}, 230$ VAC LED power supply example based on a discontinuous conduction mode (DCM) Flyback topology.

Regulation of LED Lamp Drivers With Single-Stage PFC and TRIAC Dimming has been designed by: Jong Tae Hwang at.all [10] explained: The off-the-line primary side regulation of the flyback LED lamp driver is propose dbased on LED forward voltage tracking (VFT) ) and duty variation tracking (DVT) methods, which satisfy good line / load regulation, high power factor and TRIAC dimming possibilities. This paper introduces that four derivative types (type - I to IV) are possible to implement using supply voltage, MOSFET drain voltage and duty cycle signals with the four types of sensing circuits on the basis of VFT and DVT concepts.

\section{AC/DCCONVERTER DESIGN}

The first step in the design of an AC converter with TRIAC is the placement of the load position, which can be placed on both the positive and negative sides.

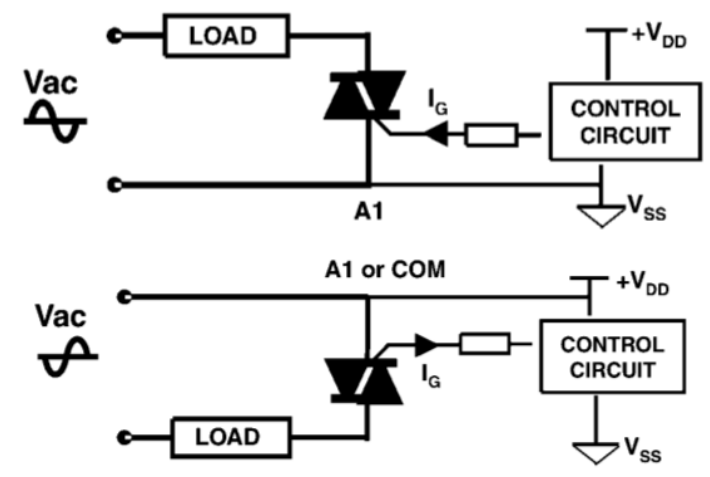

Fig. 7. TRIAC control with positive (up) and negative (down) supply

Figure 7 shows an AC converter circuit with positive controls that correspond to loads with floating grounding and those with negative controls that correspond to loads with steady ground.

Since what is needed is a DC power output with steady grounding, a TRIAC control circuit with a negative power supply is chosen, which can later be added to the rectifier and filter. The DIAC circuit as a TRIAC trigger can be designed using an $\mathrm{AC}$ voltage source by providing resistance and potentio to adjust the trigger voltage and adding a capacitor to adjust the frequency or timing of trig gering.

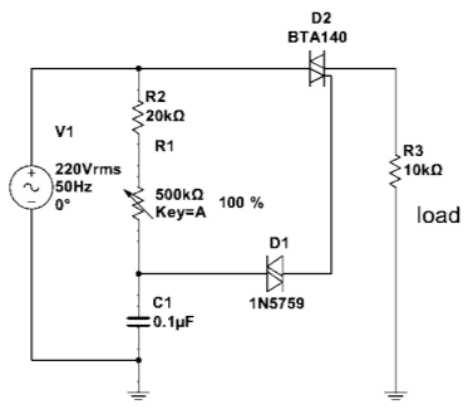

Fig. 8. DIAC circuit design 
Figure 8 shows the trigger circuit design of DIAC D1, namely by giving a positive voltage through the R1 and R2 resistor and $\mathrm{Cl}$ capacitors for triggering timing control.

\section{A. The design of the filter and the laodvoltage}

The design of the filter and rectifier circuit is still at an early stage, only to produce a rough DC output electricity, if needed a finer DC can be added to another voltage regulator, as needed. The full sine wave AC power will be cut by TRIAC D2 to a quarter wave or less according to the control of the R1 potentiometer. AC power output from TRIAC smoothed with the first capacitor $\mathrm{C} 2$, then refined again by the second capacitor $\mathrm{C} 3$, so that the output voltage has been quite flat.

The operational range of the output voltage is determined by R3 resistance which is the limiting resistance of the voltage range whose magnitude can be replaced as needed. The smaller $\mathrm{R} 3$ resistance will produce the greater the output voltage. Figure 9 is a DC power supply des ign using TRIAC that has been equipped with filters and R3 voltage regulator regulator range.

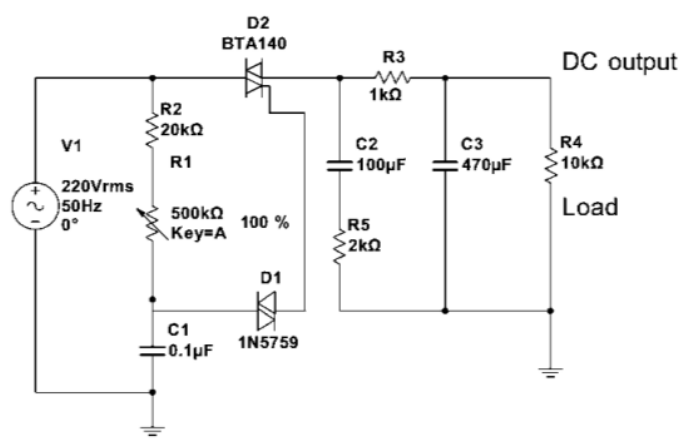

Fig. 9. Circuit design of DC power supply using TRIAC

\section{B. Experiment Design}

The 220 Volt AC power source, $50 \mathrm{~Hz}$ gives a full sine wave passed on TRIAC D2 so that only a portion of the wave passes. The amount of current through TRIAC is controlled by DIAC D1. DIAC is given a trigger voltage through resistors $\mathrm{R} 1$ and $\mathrm{R} 2$ and is delayed by capacitor $\mathrm{C} 1$. The load limiting resistor R3 functions as a voltage limiter and output current limiter. Capacitors $\mathrm{C} 1$ and $\mathrm{C} 2$ function as filters to make the DC output electricity smoother with a s mall ripple.

Thus to test the design of DC power supply can be done several steps. The first step is to install an initial resistance load R3 of $10 \mathrm{k} \Omega$, then it can be replaced in the next step of 4 $\mathrm{k} \Omega, 2 \mathrm{k} \Omega$ and $1 \mathrm{k} \Omega$. At the time of operation on each step the potentiometer R1 can be rotated to obtain the desired output voltage.

\section{RESUlTS AND DISCUSSION}

Measurements are made at each step of the initial load resistance of R3, namely at the TRIAC output point or at the point of initial load resistance input $\mathrm{R} 3$ and at the output point of R3 which has become DC power. Measurements are seen in the form of electric waves and the voltage that occurs, namely by tuming the potentiometer R1, so that the DC output voltage reaches about: $5,10,15$, up to 75 Volts.
The resistance value of DIAC $\mathrm{R}=\mathrm{R} 1+\mathrm{R} 2$ and the output DC voltage Vo is recorded, and the results are shown in Table 1.

TABLE I. DC OUTPUT Voltage

\begin{tabular}{|c|c|c|c|c|c|c|c|}
\hline \multicolumn{2}{|c|}{$\mathrm{R3}=10 \mathrm{k} \Omega$} & \multicolumn{2}{|c|}{$R 3=4 \mathrm{k} \Omega$} & \multicolumn{2}{|c|}{$\mathrm{R3}=2 \mathrm{k} \Omega$} & \multicolumn{2}{|c|}{$R 3=1 \mathrm{k} \Omega$} \\
\hline R k $\Omega$ & Volt & R k $\Omega$ & Volt & $\mathbf{R} \mathbf{k} \boldsymbol{\Omega}$ & Volt & R k $\Omega$ & Volt \\
\hline 302 & $\mathbf{0}$ & 305 & 4.9 & 319 & 5.1 & 323 & 5.5 \\
\hline 182 & 2.3 & 192 & 10.2 & 312 & 10.5 & 318 & 10.2 \\
\hline 73 & 4.2 & 84 & 15.5 & 287 & 15.3 & 301 & 15.1 \\
\hline 20 & 6.5 & 20 & 20.7 & 182 & 20.4 & 292 & 20.3 \\
\hline & & & & 44 & 25.2 & 285 & 25.6 \\
\hline & & & & 20 & 30.3 & 276 & 30.4 \\
\hline & & & & & & 262 & 35.2 \\
\hline & & & & & & 247 & 40.5 \\
\hline & & & & & & 183 & 45.3 \\
\hline & & & & & & 135 & 50.1 \\
\hline & & & & & & 92 & 55.7 \\
\hline & & & & & & 46 & 60.2 \\
\hline & & & & & & 30 & 65.5 \\
\hline & & & & & & 20 & 75.2 \\
\hline
\end{tabular}

Table 1 shows the data of the effect of changes in the resistance DIAC R, on the output voltage Vo, for each step of the initial load resistance R3, which explains that the lower $\mathrm{R}$ will produce the higher Vo. Besides that the effect of the initial resistance $\mathrm{R} 3$ load which is getting smaller will also resultin a wider and higher range of voltage.
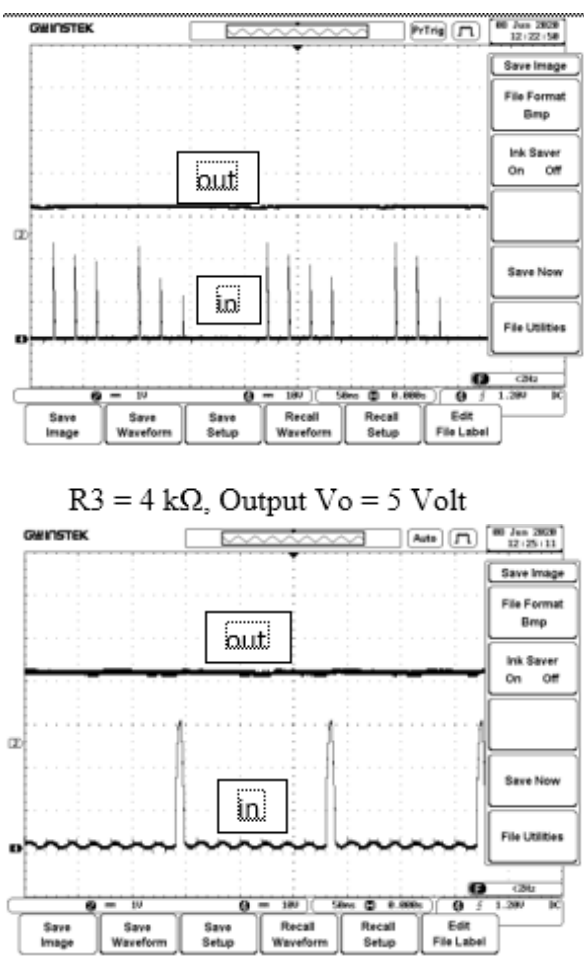

$\mathrm{R} 3=4 \mathrm{k} \Omega$, Output Vo= 15 Volt

Fig. 10. Output voltage vs R3 $=4 \mathrm{k} \Omega$ 
Figure 10 shows images of the input and output signals from $\mathrm{R} 3$ and the effect of the DIAC (R) resistors on the output voltage (Vo), which explains that the output voltage signal from TRIAC is higher but the frequency of the DIAC signal is lower. The input signal on R3 or the output from TRIAC is seen as a large positive wavy electrical signal and the output signalfrom R3 as a DC electrical signal.
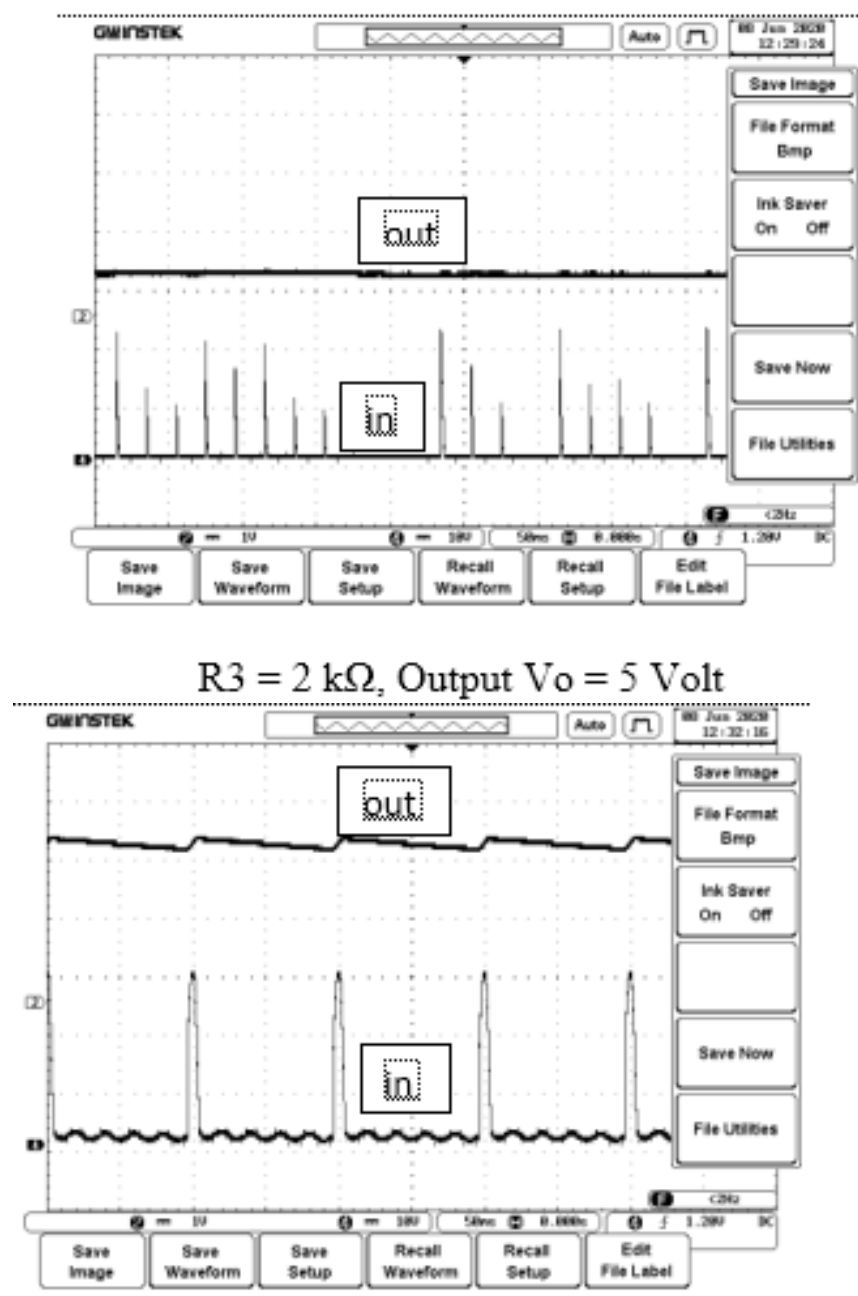

$$
\mathrm{R} 3=2 \mathrm{k} \Omega \text {, Output Vo }=25 \text { Volt }
$$

Fig. 11. Output voltage vs $\mathrm{R} 3=2 \mathrm{k} \Omega$

Figure 11 is like Figure 10 but installed $\mathrm{R} 3=2 \mathrm{k} \Omega$, showing an increasingly large input and output signal. The DC output signal tums out to be rougher, so it needs to be understood if you want a finer signal you need to add another filter.
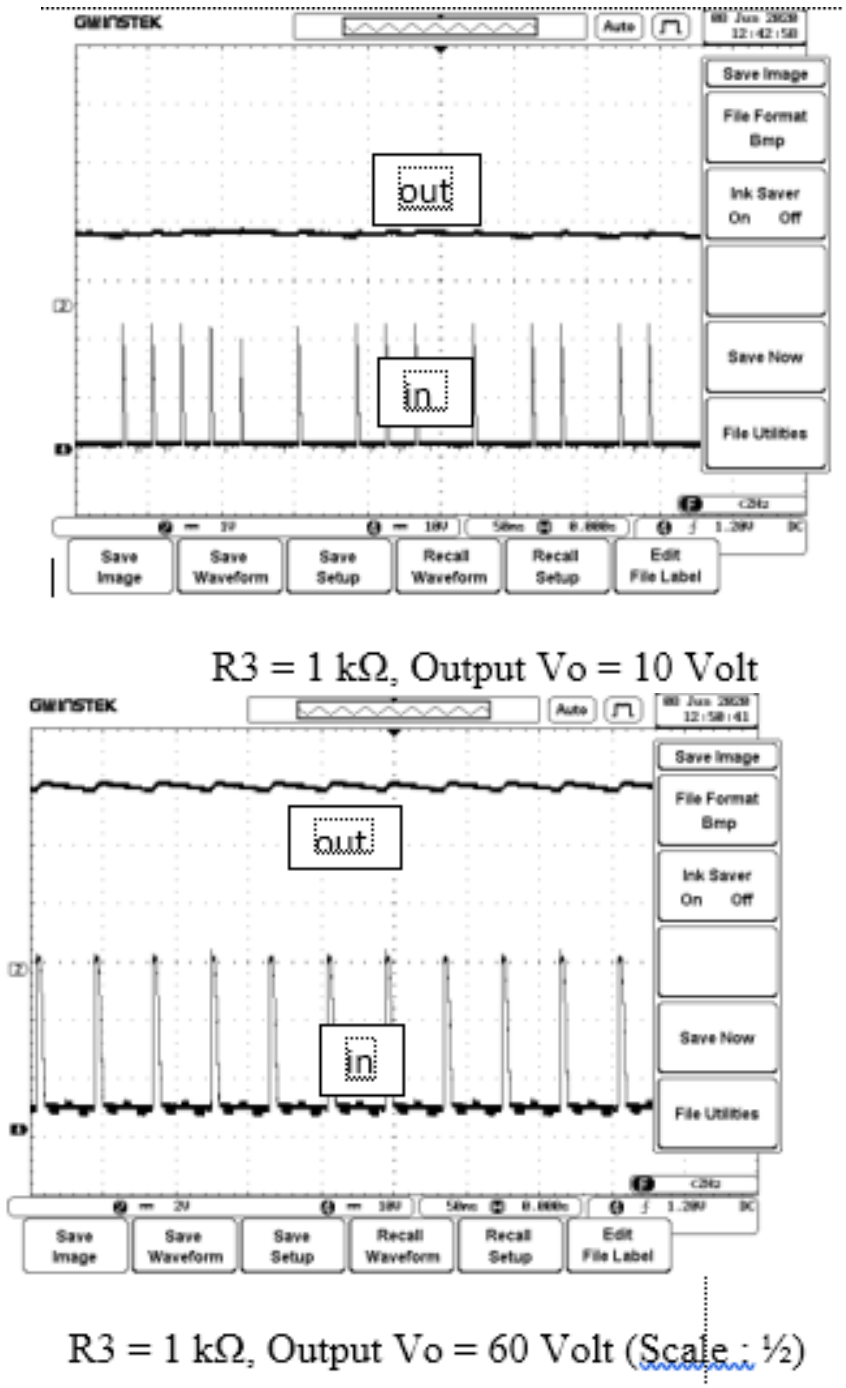

Fig. 12. Output voltage vs $\mathrm{R} 3=1 \mathrm{k} \Omega$

Figure 12 shows a higher output signal, but not linear to large changes in R3. Here the output voltage rises very high, so it needs attention to changes in extemal loads that can change the output voltage that is too high.

The measurement data processing is then carried out to obtain a more detailed description of the effect of DIAC resistance and initial load resistance.

Figure 13 shows a graph of the effect of DIAC resistance and initial load resistance in 2 dimensions (2D) and three dimensions (3D), which explains that the effect of such resistance is not linear, but not continuous. At first the change in output voltage is quite gentle at the beginning and end, but in the middle area is very sharp. 

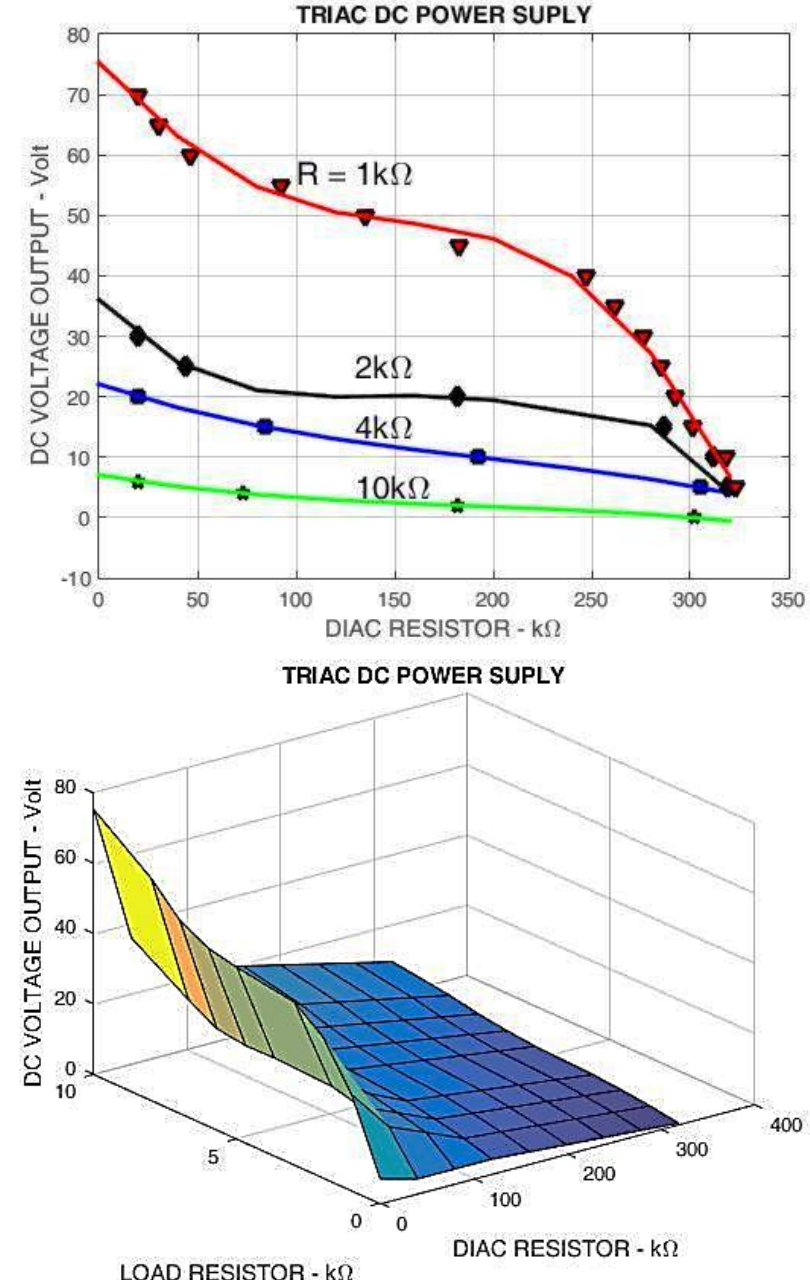

Fig. 13. 2D and 3D Graph of Vo vs R

\section{CONCLUSION}

With the aim to design and test a wide range of variable DC power supply using TRIAC it has been able to do well. Even though it has just produced a simple initial design, the main thing has been achieved, namely in the form of an AC to DC converter using TRIAC that is able to work at high voltage, without a transformer, which provides variable output voltage, lightweight, efficient and inexpensive. The ability of this converter is that it can produce a voltage of 5 to 75 Volts, with a range of 5 to 20 Volts on $\mathrm{R} 3=4 \mathrm{k} \Omega$, a range of 5 to 30 Volts on $\mathrm{R} 3=2 \mathrm{k} \Omega$, a range of 5 to 75 Volts on $\mathrm{R} 3=1 \mathrm{k} \Omega$. Graphic characteristics of this converter have also been provided in 2D and 3D.

\section{REFERENCES}

[1] Alber Paul Malvino, Electronic Priciples, Mc Graw Hill Inc, 1984.

[2] ON Semiconductor, BTA16-600CW3/D Data Sheet, Semiconductor Components Industries, LLC, 2012.

[3] Mahmood Nahvi, Joseph A. Edminister, Electric Circuits, Schaum's Outlines, Mc Graw Hill, 1983.

[4] Taitron, DB3 Bidirectional DIAC Trigger Diode, Taitron Componets Incorporated, Shanghai, Cina, 2018.

[5] ON Semiconductor, Switch Mode Power Supply, Semiconductor Components Industries, LLC, 2014.

[6] A. Sujono, Developing Wide Flexible Robust PWM Driver by Flip Flop For Supporting The SMPS Technology, JEEICT, e-ISSN : 9772715126009, Vol 2, N0.1, 25-29, https://dx.doi.org/10.20961/ieeict.2.1.41352, 2020.

[7] Chih-Wei Lin and Ying-Yu Tzou, Digital Voltage Control of Boost CRM PFCAC/DC Converters with TRIAC Phase Control Dimmer, IEEE Xplore, 978-1-4673-2868-5112/2012.

[8] Peter I. Yakimov, Digital Synchronisation with Mains for the Purpose of the Phase Motion Control, IFAC (International Federation of Automatic Control) Hosting by Elsevier Ltd. All rights reserved. Peer review under responsibility of International Federation of Automatic Control. 10.1016/j.ifacol.2015.12.053, 2405-8963 @ 2015.

[9] Montu Doshi and James Patterson, Input Filter Design for TRIAC Dimmable LED Lamps, IEEE Xplore., 978-1-4799-0336-8/13/\$31.00 (C)2013.

[10] Jong Tae Hwang, Moon Sang Jung, Dae Ho Kim, Jun Hong Lee, Min Ho Jung, and Jong Ha Shin, Off-the-Line Primary Side Regulation LED Lamp Driver With Single-Stage PFC and TRIAC dimming Using LED Forward Voltage and Duty Variation Tracking Control, IEEE JOURNAL OF SOLID - STATE CIRCUITS, VOL. 47, NO. 12, DECEMBER 2012. 